\title{
Vertebral rim lesions in the dorsolumbar spine
}

\author{
R. C. HILTON AND J. B A LL \\ From the Department of Rheumatology, Hope Hospital, Manchester
}

SUMmarY The frequency, distribution, and histological characteristics of vertebral rim lesions have been studied at D11 and L4 in 117 post-mortem spines in subjects aged 13-96 years. Only one lesion was found in patients $<30$ years, but thereafter the frequency increased with age. At least one rim was affected in the majority of patients $\geqslant 50$ years. They were found more frequently in the upper than the lower rim and they were also more common anteriorly than posteriorly. Lesions were associated with focal avulsion of the annulus in an otherwise healthy disc or with annular tears running into the rim. Rim lesions can be recognised radiographically by the presence of the vacuum phenomenon, vertebral rim sclerosis with or without a cup-shaped defect in the rim and osteophytes confined to one side of the disc. The histological appearances suggest a traumatic aetiology, and since bone is known to be supplied with pain sensitive nerve endings the lesions may be important in the general context of low back pain.

Eradication of the stimulus to pain sensitive nerve endings is a logical way of treating pain arising from the musculoskeletal system, but in the case of low back pain this is rarely possible because of the clinician's inability to identify the precise source of discomfort.

In the lumbar and dorsal region of the adult spine both the upper and lower surfaces of each vertebral body are ringed by a slightly raised rim of compact bone. ${ }^{1}$ The rim is formed by the ossification of the cartilaginous epiphyseal ring and its subsequent fusion to the adjacent bone during adolescence. ${ }^{12}$

Lateral radiographs of the lumbar spine sometimes show focal sclerosis in the rim of a vertebral body, often without any associated abnormality of the adjacent disc. Although these vertebral rim lesions are situated close to the longitudinal ligament and hence may be a potential source of low back pain, no information about them has been recorded. We have therefore investigated their frequency, distribution, and histological characteristics as part of a systematic study of the spine below D9.

\section{Materials and methods}

The material consisted of 124 selected post-mortem specimens of the lower spine. Spines were not removed from patients with known trauma, neoplasia, metabolic or infective bone disease, or if they

Accepted for publication 23 March 1983.

Correspondence to Dr R. C. Hilton, Department of Rheumatology, Hope Hospital, Eccles Old Road, Salford M6 8HD. had received prolonged corticosteroid therapy. Histological examination of an undecalcified bone block from the sacrum of each spine revealed 6 patients with osteomalacia and one with mild secondary hyperparathyroidism. These patients were excluded from the study. The remaining 117 included 52 females and 65 males. The age range was 13-96 years. Fifty-four patients were aged under 50 years and 63 patients were aged 50 years or over.

ASSESSMENT OF RIM LESIONS

After removal of the neural arches the vertebral bodies were divided into 5 sagittal slabs and then radiographed. In all cases a histological section of the disc and adjacent bone was taken from the central slab of the D11 and L4 segments. Occasionally other segments were also examined as indicated by the radiographic appearances. Each section was examined systematically, and the histological features of each vertebral rim were recorded. The annular tears were scored for all discs as previously described. ${ }^{3}$

The bone density of the complete central slab of L3 was measured by Archimedes' principle with a pyknometer.

\section{Results}

The normal vertebral rim (Fig. 1) showed no discontinuities in the bony rim, no disruption of the annular fibres at their attachment, and no abnormality in the underlying haemopoietic marrow. 


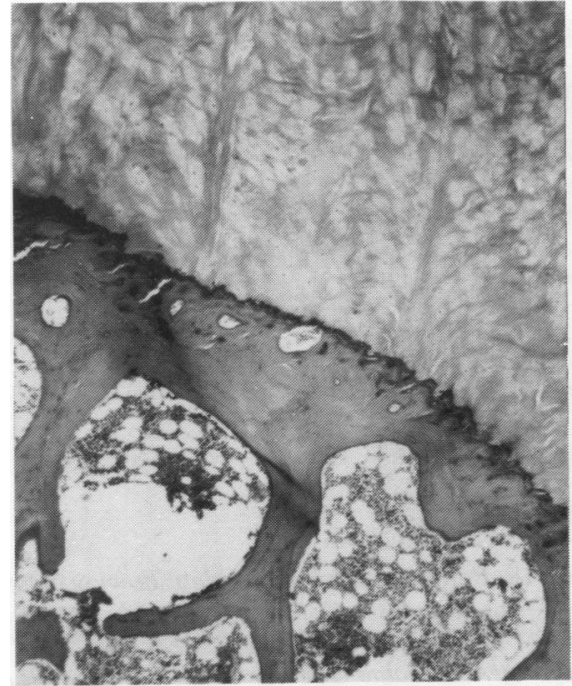

Fig. 1 Normal vertebral rim to show intact bony rim, intact annular attachment and the presence of haemopoiesis in adjacent marrow. $(H E, \times 30)$.
GENERAL CHARACTERISTICS OF RIM LESIONS Radiographs of the vertebral slab sections indicated that rim lesions were usually focal and affected only a few millimetres of the circumference. Hirtologically they were characterised by the presence of discontinuities and disorganisation of the bone of the vertebral rim at the attachment of the annulus (Figs. 2-5). This lesion was associated either with a focal avulsion of the annulus (Figs. 2 and 4 ) or a major tear of the annulus running into the rim (Fig. 5). The avulsed annulus may be recognised radiographically as a small translucency (clinically sometimes referred to as the vacuum phenomenon) (Fig. 2). Rarely this gap was filled by fibrous and fibrocartilaginous tissue, the structure of which was clearly different from the normal annulus (Fig. 3), especially when examined between crossed polars. In the underlying marrow there were typically loss of haemopoiesis, some oedema, and occasionally haemorrhage (Figs. 2-5). Inflammatory cell infiltration was invariably extremely scanty and usually absent. The lesion at the surface of the rim was associated with sclerosis of the subjacent bone trabeculae (Figs. 2 and 5), and rarely
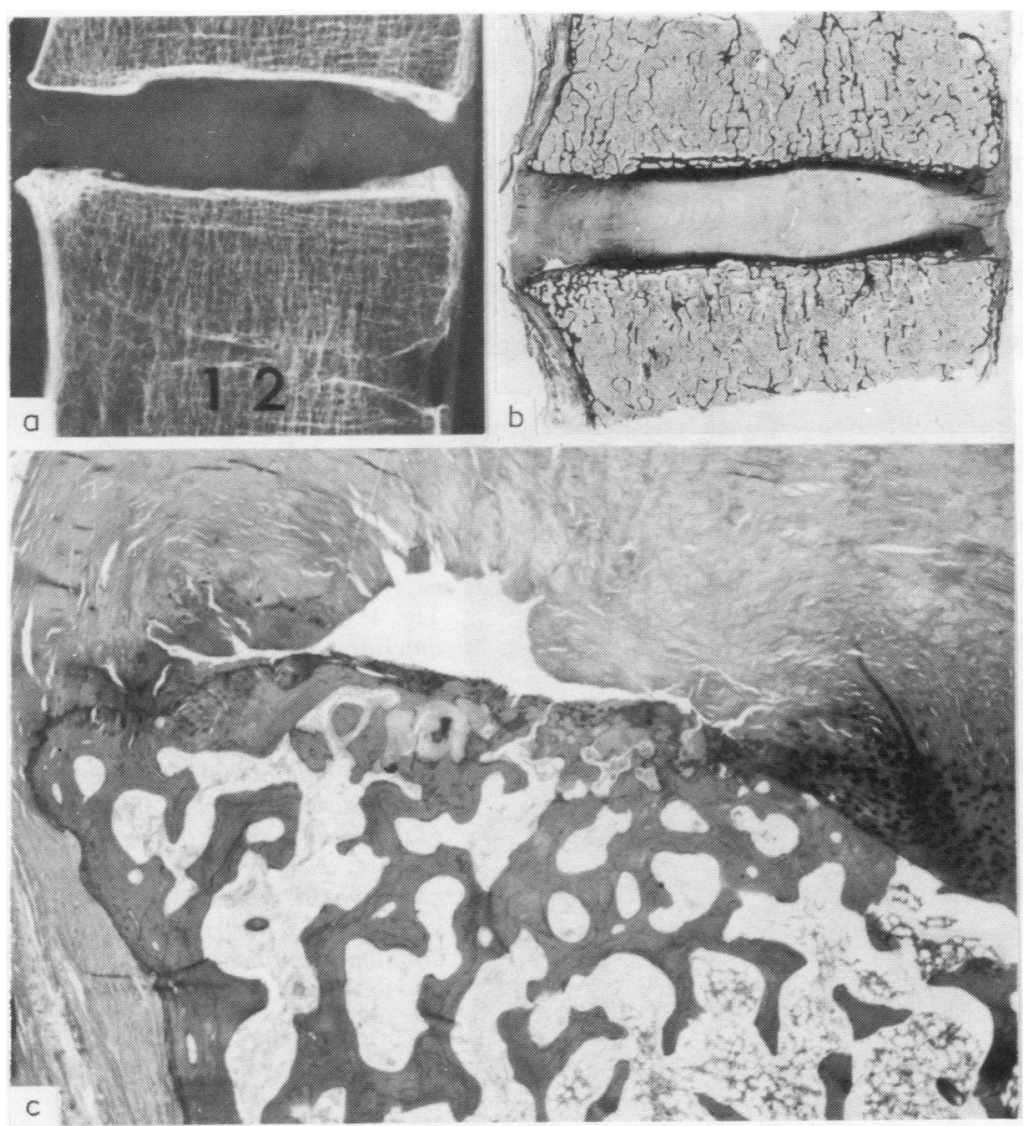

Fig. 2 Rim lesion (commonest type) at upper anterior corner of D12 in a female aged 33 years. (a) Radiograph of sagittal slab showing localised sclerosis and $a$ translucency at the site of a tear in the annular attachment. (b) Histological section of segment shown in (a) confirming the presence of a tear in the annular attachment and snowing subjacent trabecular sclerosis. The rest of the intervertebral disc is normal. (HE, $\times 1.5$ ). (c) Part of lesion shown in (b) showing internally the normal cartilage and externally an avulsion of the annulus. The detached annulus contains a few specks of calcified cartilage anteriorly. Discontinuities plugged with fibrocartilaginous callus are present in the vertebral rim. The underlying cancellous trabeculae are sclerotic and the marrow in this region is oedematous and lacks

haemopoietic tissue. $(H E, \times 24)$. 

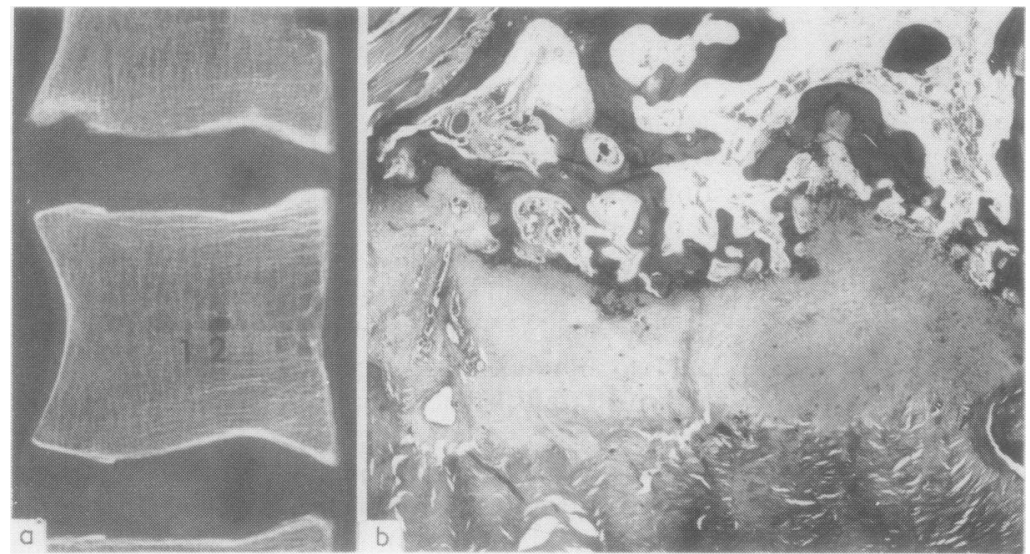

Fig. 3 Rim lesion in lower anterior rim of D11 in a male aged 36 years. (a) Radiograph of sagittal slab showing localised sclerosis and a cup-shaped defect in an otherwise normal disc. (b) Part of the rim lesion shown in (a) showing discontinuities in the bony rim and loss of the overlying cartilage indicating severe damage. There is also hyperaemia, oedema, loss of haemopoiesis in the narrow, and sclerosis of the underlying cancellous bone trabeculae. The cup-shaped defect in the bony rim is joined to the annulus by new fibrous and fibrocartilaginous tissue which is avascular apart from at its outer edge. The presence of this tissue suggests healing but the reconstruction of the rim/annulus junction is still imperfect and the presence of oedema in the marrow below indicates persistent tissue damage. $(H E, \times 24)$.

the sclerosis surrounded a cup-shaped defect in the surface of the rim (Fig. 3). In severe lesions microfractures of the bone trabeculae might be seen immediately below the surface of the rim.

Where a rim lesion was associated with an annular tear, vascularisation of the tear adjacent to the rim was common (Fig. 5). The small thin-walled vessels appeared to arise in the marrow and/or the outer annulus.

Most rim lesions showed evidence of attempted repair in the form of fibrovascular and/or fibrocartilaginous tissue and reactive bone in the region of the bony rim (Figs. 2, 3, and 4). However, complete restitution of the discontinuity between the rim and the annulus was much less frequent and was found in only 8 of the 113 anterior rim lesions encountered in the systematic study of D11 and L4.

DISTRIBUTION OF RIM LESIONS

Examination of all the histological sections from the

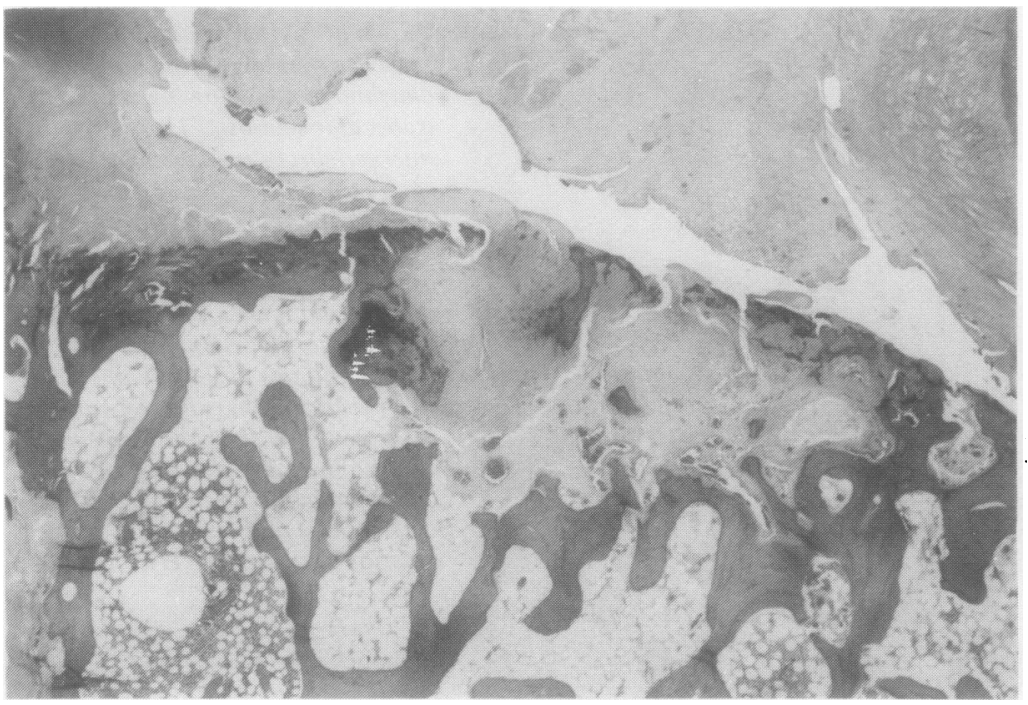

Fig. 4 Rim lesion in upper anterior plate of $L 2$ in a male aged 69 years. A cup-shaped defect in the bone of the vertebral rim is filled by fibrous and fibrocartilaginous tissue containing bone fragments, but the disruption of the attachment of the annular fibres to the rim persists. There is loss of haemopoiesis in the adjacent marrow and a horizontal tear at the annular attachment. (HE, ×24). 


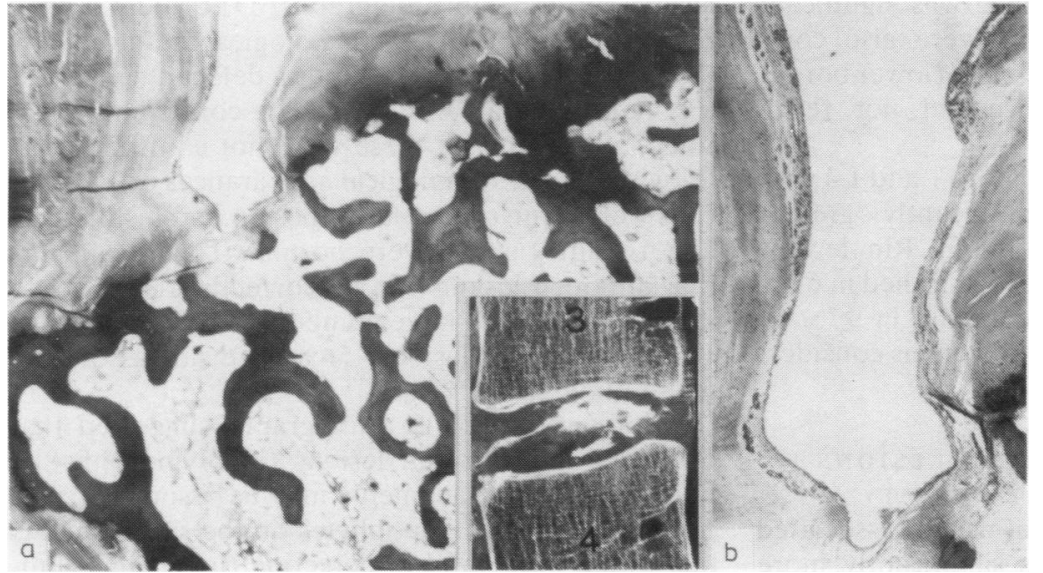

Fig. 5 (a) Rim lesion in the upper anterior plate of L4 in a male aged 66 years associated with an oblique annular tear shown (inset) in a discogram. $(H E, \times 24)(b)$ The tear shown in (a) is lined with vascular tissue. $(H E, \times 30)$.
D11 and L4 segments revealed lesions in 113/468 anterior rims and in $47 / 468$ posterior rims (Table 1 ). The frequency of rim lesions increased with age and in cases under 30 years only one lesion was observed. This was posteriorly in the male aged 22 years. Between 30 and 49 years of age 11/68 anterior rims in males and 14/56 anterior rims in females were affected. Posteriorly in the same age group 3/68 rims in males and 2/56 rims in females were affected. In patients aged 50 years or over $56 / 144$ anterior rims in males and 32/108 anterior rims in females were affected. Posteriorly in the same age group the rim was affected on 22/144 occasions in males and on $19 / 108$ occasions in females.
In females the number of lesions in the anterior rims at D11 (21/104 was similar to the number at $L 4$ $(25 / 104)$, but in males the number at D11 (19/130) was considerably less than at L4 (48/130) (Table 1). Thus in males there was a significantly greater frequency of anterior lesions at L4 than at D11 $(p<0.005)$, and the frequency at L4 in males was also significantly greater than at the same disc level in females $(p<0 \cdot 05)$.

Anterior rim lesions were commoner in the upper vertebral end-plate (lower border of the disc) than in the lower vertebral end-plate (upper border of the disc) in both males and females (Table 1), and when the results for the 2 sexes and the 2 discs (D11 and

Table 1 Distribution of anterior and posterior rim lesions (number) by sex, age, vertebral end-plate, and disc level.

\begin{tabular}{|c|c|c|c|c|c|c|c|c|c|c|}
\hline & \multicolumn{5}{|c|}{ Anterior } & \multicolumn{5}{|c|}{ Posterior } \\
\hline & \multicolumn{5}{|c|}{ Age group } & \multicolumn{5}{|c|}{ Age group } \\
\hline & 30 & $30-49$ & $50-69$ & 70 & Total & 30 & $30-49$ & $50-69$ & 70 & Total \\
\hline $\begin{array}{l}\text { Males D11 } \\
\text { Upper } \\
\text { Lower }\end{array}$ & $\begin{array}{l}0 \\
0\end{array}$ & $\begin{array}{l}1 \\
2\end{array}$ & $\begin{array}{l}5 \\
5\end{array}$ & $\left.\begin{array}{l}4 \\
2\end{array}\right\}$ & $19^{+}$ & $\begin{array}{l}0 \\
0\end{array}$ & $\begin{array}{l}0 \\
0\end{array}$ & $\begin{array}{l}1 \\
3\end{array}$ & $\left.\begin{array}{l}2 \\
1\end{array}\right)$ & 7 \\
\hline $\begin{array}{l}\text { Males L4 } \\
\text { Upper } \\
\text { Lower }\end{array}$ & $\begin{array}{l}0 \\
0\end{array}$ & $\begin{array}{l}3 \\
5\end{array}$ & $\begin{array}{l}10 \\
19\end{array}$ & $\left.\begin{array}{l}5 \\
6\end{array}\right\}$ & $48+^{*}$ & $\begin{array}{l}0 \\
1\end{array}$ & $\begin{array}{l}2 \\
1\end{array}$ & $\begin{array}{l}2 \\
6\end{array}$ & $\left.\begin{array}{l}4 \\
3\end{array}\right)$ & 19 \\
\hline $\begin{array}{l}\text { Females D11 } \\
\text { Upper } \\
\text { Lower }\end{array}$ & $\begin{array}{l}0 \\
0\end{array}$ & $\begin{array}{l}0 \\
6\end{array}$ & $\begin{array}{l}3 \\
5\end{array}$ & $\left.\begin{array}{l}3 \\
4\end{array}\right\}$ & 21 & $\begin{array}{l}0 \\
0\end{array}$ & $\begin{array}{l}0 \\
0\end{array}$ & $\begin{array}{l}4 \\
4\end{array}$ & $\begin{array}{l}1 \\
0\end{array}$ & 9 \\
\hline $\begin{array}{l}\text { Females L4 } \\
\text { Upper } \\
\text { Lower }\end{array}$ & $\begin{array}{l}0 \\
0\end{array}$ & $\begin{array}{l}3 \\
5\end{array}$ & $\begin{array}{l}4 \\
4\end{array}$ & $\left.\begin{array}{l}3 \\
6\end{array}\right\}$ & $25^{*}$ & $\begin{array}{l}0 \\
0\end{array}$ & $\begin{array}{l}0 \\
2\end{array}$ & $\begin{array}{l}1 \\
3\end{array}$ & $\begin{array}{l}2 \\
4\end{array}$ & 12 \\
\hline Total & 0 & 25 & 55 & 33 & $113^{* *}$ & 1 & 5 & 24 & 17 & $47^{* *}$ \\
\hline
\end{tabular}

Upper = vertebral plate at upper border of disc. Lower = vertebral plate at lower border of disc.

$* p<0.05$.

$+p<0.005$.

${ }^{* *} p<0.005$. 
L4) were combined this difference was significant $(p<0.005)$. Posterior rim lesions were also commoner in the upper vertebral end-plate (lower border of the disc), but the difference did not reach significance.

The total number of rim lesions (D11 and L4 with the sexes combined) was significantly greater anteriorly than posteriorly $(p<0 \cdot 0005)$. Rim lesions were present at one or both the levels studied in $63 \%$ of cases aged between $30-49$ years and in $97 \%$ of cases aged 50 years or over, but there was considerable variation in severity.

RELATIONSHIP OF ANTERIOR RIM LESIONS TO VASCULARISATION AND BONE DENSITY

Vascularisation in the annulus was usually associated with a peripheral tear and was significantly more frequent in the anterior annulus than in the posterior annulus at both L4 and D11 ( $p<0.001)$.

Anterior rim lesions showed a high degree of association with vascularisation in the adjacent annulus $(p<0.0005)$, thus suggesting that a vertebral rim defect was one factor determining the presence of annular vascularisation.

No relationship was found between the presence of anterior rim lesions and bone density.

\section{RELATIONSHIP OF ANNULAR TEARS TO THE VERTEBRA L RIM}

Analysis of the annular tear charts reveals that tears occurred at various sites in the annulus. Most tears were centrally placed in the disc, but there were spines in which at one or more disc levels anterior and/or posterior tears were closely related to the vertebral rim. These tears, which may run either obliquely to the rim (Fig. 5) or horizontally above the rim (Figs. 2 and 4), were commoner anteriorly than posteriorly and reached their highest frequency between L1 and L4. Anteriorly, at each of the discs from $\mathrm{L} 1$ to $\mathrm{L} 4$ inclusive in males and at $\mathrm{L} 3$ and $\mathrm{L} 4$ in females, there were significantly more tears at the lower annular/rim junction (upper border of vertebra) than at the upper annular/rim junction (lower border of vertebra) $(p<0.05)$.

Tears, particularly in older patients, were extremely frequent, and this made it difficult to analyse their relationships with other abnormalities. However, tears with a component that ran either obliquely to a rim or horizontally just above a rim were much less frequent, and anterior tears of this nature showed a significant relationship with discontinuities in the underlying bony $\operatorname{rim}(p<0 \cdot 005)$.

RADIOLOGICAL IDENTIFICATION OF ANTERIOR RIM LESIONS

To determine the accuracy of detecting anterior rim lesions on the slab radiographs, D11 and L4 were read independently of the histological findings. With the presence of sclerosis and/or a defect at the rim as the main criteria, 47 lesions were confidently identified, and only 4 of these were not confirmed histologically. The radiological appearances of 10 other rims were equivocal, and of these 6 had histological abnormalities and 4 were normal. Thus it appears that although lesions can be correctly identified on slab radiographs, a large number (64 out of a total of 113 anterior rim lesions; $56 \%$ ) are not associated with radiological changes.

Examination of slab radiographs suggested that one-sided anterior rim lesions (involving only the upper or lower attachment) may be associated with one-sided anterior osteophytes on the same rim. As this would be helpful in detecting rim lesions clinically, all the lateral films of the intact spines were examined for one-sided osteophytes, and at D11 and L4 the findings were correlated with the results of the histological examination. In the 54 patients under 50 years there were 6 discs with one-sided osteophytes, 4 of which had rim lesions. Similarly in the 63 patients aged 50 years or over 13 out of 19 discs with onesided osteophytes had rim lesions. Thus $68 \%(17 / 25)$ of one-sided osteophytes were associated with rim lesions, and this relationship was statistically significant $(p<0 \cdot 001)$. With three exceptions the one-sided osteophytes were on rims at the lower border of the disc (upper border of the vertebra).

\section{Discussion}

This study has shown that vertebral rim lesions occur frequently in the dorsolumbar spine, but we have found no mention of them in the literature. They were characteristically focal and associated with a discontinuity in the bony rim of up to about $5 \mathrm{~mm}$ in diameter, an avulsion or a tear of the adjacent annulus, oedema, loss of haemopoiesis, haemorrhage in the adjacent marrow, vascularisation of associated annular tears, and sclerosis of bone adjacent to the rim defect. Inflammatory cell infiltration was very inconspicuous or more often absent. These findings suggest a traumatic aetiology, and this conclusion is supported by the preponderance of rim lesions in the end-plate at the lower border of the disc, a site which corresponds with that of major traumatic fracture. ${ }^{4-6}$

Occasionally the radiological features of a rim lesion resemble those referred to as anterior Schmorl's nodes (Fig. 3a). However, the histology suggests a traumatic aetiology, whereas the typical Schmorl's node is thought to be a developmental defect restricted to the cartilage end-plate. ${ }^{7}$ The type of cup-shaped rim lesion depicted by Fig. 3a closely resembles lesions sometimes seen in ankylosing 
spondylitis which have been variously regarded as inflammatory or traumatic. ${ }^{8}$ The present findings support the latter interpretation.

Brittlecoat analysis has been used to identify the stresses on isolated vertebrae subjected to compression loading. ${ }^{9}$ High track densities due to tensile stresses were found near the vertebral rim, particularly anteriorly and laterally. This finding could be of relevance to the pathogenesis of so called 'anterior Schmorl's nodes' in teenagers ${ }^{10}$ and rim lesions in adults. It is possible that relatively minor trauma anteriorly predisposes to 'anterior Schmorl's nodes' before the union of the epiphyseal ring with the vertebral body, but thereafter to lesions of the type described in the present study.

The clinical significance of the present findings remains to be established. The tissue damage and microfractures found in the vertebral rim could mean that the lesions have the potential to cause pain, since pain-sensitive nerve endings have been demonstrated in bone and in the outer anterior annulus. ${ }^{11}$ As rim lesions may occur in discs with neither disc narrowing nor osteophytes, their clinical detection may be of importance in the general context of low back pain, especially in middle-aged subjects with apparently normal $x$-rays.

In the present study only $44 \%$ of rim lesions could be recognised on the slab radiographs, and clinically the percentage is likely to be smaller. Nevertheless, those that can be recognised are usually the most extensive, and there are 3 radiological signs which promote their detection. Firstly, with the spine in extension, a small translucency may be seen in rim lesions associated with avulsion of the annular attachment. Secondly, there may be sclerosis of the vertebral rim. Thirdly the presence of an osteophyte on only one side of the disc (usually the lower border) strongly suggests an adjacent rim defect. Although only the D11 and L4 segments were systematically examined histologically, it is clear that rim lesions may occur at any level below D10. The present study indicates that they are commoner in the lower lumbar region than at higher levels, especially in males, commoner anteriorly than posteriorly, and commoner in the upper vertebral rim than the lower vertebral rim.

Only one rim lesion was found in the mature spine up to the age of 30 . Thereafter their frequency gradually increases, but the high frequency in the elderly is at least partly the result of a cumulative effect, since evidence of complete restitution is rarely seen.

\section{References}

1 Schmorl G, Junghanns $\mathrm{H}$. The human spine in health and disease. 2nd American ed. London: Grune and Stratton, 1971: 3-14.

2 Williams P L, Warwick R, eds. Gray's anatomy. London: Churchill Livingstone, 1980: 283.

3 Hilton R C, Ball J, Benn R T. Annular tears in the dorsolumbar spine. Ann Rheum Dis 1980; 39: 533-8.

4 Jefferson G. Discussion on spinal injuries. Proc $R$ Soc Med 1927; 21: 625-37.

5 Nicoll E A. Fractures of the dorsolumbar spine. J Bone Joint Surg 1949; 31B: 376-94.

6 Howorth H B. Fracture of the spine. Am J Surg 1956; 92: 573-93.

7 Hilton R C, Ball J, Benn R T. Vertebral end-plate lesions (Schmorl's nodes) in the dorsolumbar spine. Ann Rheum Dis 1976; 35: 127-32.

8 Cawley M I D, Chalmers T M, Kellgren J H, Ball J. Destructive lesions of vertebral bodies in ankylosing spondylitis. Ann Rheum Dis 1972; 31: 345-58.

9 Shah J S, Wills H H. Experimental stress analysis of the lumbar spine. In: Jayson M I V, ed. The lumbar spine and back pain. London: Sector Publishing, 1980: 371-5.

10 Edgren W, Vainio S. Osteochondrosis juvenilis lumbalis. Acta Chir Scand 1957; suppl 227.

11 Yoshizawa H, O'Brien J P, Smith T W, Trumper M. The neuropathology of intervertebral discs removed for low back pain.J Pathol 1980; 132: 95-104. 